\title{
A terapia celular no tratamento da isquemia crítica dos membros inferiores
}

\author{
Cell therapy for the treatment of critical ischemia of the lower limbs
}

\section{José D almo de Araújo', José D almo de Araújo Filho², Emerson Ciorlin², Milton Artur Ruiz', Lílian Piron Ruiz', 0 swaldo Tadeu G reco ${ }^{5}$, M ario Roberto Lago ${ }^{6}$, Roberto Vito Ardito ${ }^{7}$}

\begin{abstract}
Resumo
Os autores fazem um histórico sobre as pesquisas com célulastronco embrionárias e do cordão umbilical, suas respectivas vantagens e desvantagens. Seguem com as discussões sobre células-tronco adultas, sua definição, histórico, fontes e participação nos processos de regeneração tecidual, particularmente no endotélio. Ressaltam a importância de fatores que mobilizam as células-tronco adultas a partir da medula óssea: citocinas, angiopoietinas e outros fatores de crescimento. As células-tronco adultas mobilizam-se sob a forma de células endoteliais progenitoras, que têm origem comum com as células endoteliais a partir dos hemangioblastos. $0 \mathrm{~s}$ fatores de mobilização manifestam-se em condições de hipoxia e fazem com que as células endoteliais progenitoras se local izem nos locais de isquemia para produzir a neovasculogênese, que se faz por três possíveis mecanismos: a angiogênese (formação de novos capilares a partir de brotos de capilares já existentes), a arteriogênese (relacionada à circulação colateral) e a vasculogênese (vasos real mente novos). Fazem, a seguir, uma análise da literatura relativa à experimentação animal e aos estudos clínicos. Concluem ressaltando que as células-tronco adultas, embora tenham um grande potencial de uso, ainda demandam muito estudo e pesquisa para se firmar como método terapêutico.
\end{abstract}

Palavras-chave: terapia celular, células tronco, isquemia crítica.

1. Chefe do Serviço de Cirurgia Vascular, Instituto de Moléstias Cardiovasculares de São José do Rio Preto, SP.

2. Cirurgião, Serviço de Cirurgia Vascular, Instituto de Moléstias Cardiovasculares de São José do Rio Preto, SP. Especialista em Cirurgia Vascular pela Sociedade Brasileira de Angiologia e Cirurgia Vascular e Associação Médica Brasileira.

3. Livre-docente, Faculdade de Medicina de São José do Rio Preto (FAMERP), São José do Rio Preto, SP. Coordenador da Unidade de TMO Hospital de Base de São José do Rio Preto. Coordenador do Grupo de Estudos de Terapia Celular, Instituto de Moléstias Cardiovasculares (IMC), São José do Rio Preto, SP

4. Médica assistente, Unidade de TMO, Hospital de Base de São José do Rio Preto e Grupo de Estudos de Terapia Celular, IMC, São José do Rio Preto, SP.

5. Doutor. Professor, FAMERP. Médico cardiologista e diretor científico, IMC, São José do Rio Preto, SP.

6. Biomédico. Pós-Graduação em Hematologia.

7. Cirurgião cardíaco, especialista pela Soc. Brasileira de Cirurgia Cardiovascular e chefe da Cirurgia Cardíaca, IMC, São José do Rio Preto, SP.

Artigo submetido em 04.10.05, aceito em 31.10.05.

$\mathrm{J}$ Vasc Br 2005;4(4):357-65.

Copyright $\odot 2005$ by Sociedade Brasileira de Angiologia e Cirurgia Vascular.

\begin{abstract}
The authors review the history of the researches on embryonic and umbilical cord vein stem cells, their advantages and disadvantages. They proceed with comments on adult stem cells, their concept, history, sources and role on tissue regenerative processes, mainly on the endothelium. They stress the importance of factors that mobilize the adult stem cells from the bone marrow: cytokines, angyopoietine and other growth factors. The adult stem cells are mobilized as endothelial progenitor cells, which have a common origin with the endothelial cells from the hemangioblasts. The mobilizing factors are activated under hypoxia and promote the homing of the endothelial progenitor cells on the ischemic sites in order to generate the neovasculogenesis, which is accomplished through three possible mechanisms: angiogenesis (new capillaries from sprouts of the existing ones), arteriogenesis (related to collateral circulation) and vasculogenesis (actual new vessels). An appraisal of the literature is made with regard to animal and clinical sets Finally, they stress that adult stem cells, although bearing an enormous potential, still demand a considerable amount of work to become a current therapeutic
\end{abstract} method.

Key words: cell therapy, stem cells, critical limb ischemia.

Os primeiros pesquisadores a descreverem uma célula-tronco em embriões humanos foram Thomson et al., em 19981. Era célula retirada da cavidade dos blastocistos de embriões utilizados em técnicas de reprodução assistida (Figura 1). T ratava-se de células não diferenciadas, chamadas pluripotentes, pois poderiam se multiplicar e se transformar em qualquer tipo de tecido de qualquer dos três folhetos embrionários: ectoderma, mesoderma e endoderma.

As dificuldades para se produzir embriões e também a autorização para o seu uso, além dos problemas éticos e legais, têm conseguido diminuir o ritmo e os investimentos financeiros nas pesquisas com célulastronco embrionárias. Além disso, estas sempre têm a possibilidade de provocar reações imunológicas. Por 


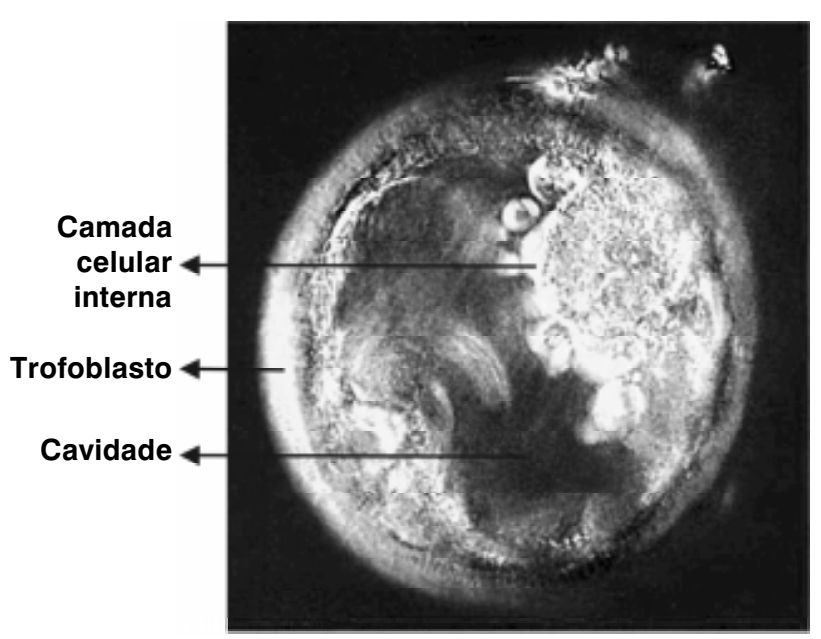

Figura 1 - Blastocisto (5-7 dias)

outro lado, a clonagem de células do próprio paciente, que eliminaria esse problema, necessita da doação de um óvulo feminino, o qual deve ser colhido com técnicas invasivas.

Para complicar ainda mais, o número de células embrionárias coletadas com as técnicas correntes é pequeno e insuficiente para que se efetivem as ações terapêuticas usualmente pretendidas. $H$ á necessidade de se fazerem culturas com técnicas especiais e por tempo relativamentelongo (em torno de 10 a 15 dias).

Por isso tudo, as pesquisas em terapia celular têmse desenvolvido com mais intensidade com célulastronco do sangue do cordão umbilical e células-tronco adultas (CTA).

As células do sangue do cordão umbilical humano teriam aplicação específica para o próprio recém-nascido e seriam armazenadas para uso futuro, quando necessário. Eventualmente, poderiam ser usadas em gêmeos univitelinos ou em outras pessoas que apresentassem uma tipagem H LA (H uman Leucocyte Antigen) adequada. Poderiam ser usadas, ainda, em pacientes não compatíveis, simultaneamentecom imunossupressores. É uma linha de pesquisa promissora, e a prova disso é a proliferação de bancos de cordão umbilical públicos e privados.

A pesquisa com CTA éo grande acontecimento da atualidade. Além de serem operacionalmente mais fáceis, não apresentam os problemas ético-religiosos das células embrionárias. Por outro lado, são células embri- ologicamente mais evoluídase, por isso, com um caminho menor a percorrer até a sua diferenciação, o que diminui o risco de desvios ontogênicos e de outros efeitos colaterais.

\section{Células-tronco adultas}

São células indiferenciadas que podem se renovar e reproduzir indefinidamente e, sob certos estímulos, se transformar em células especializadas de diferentes tecidos ou órgãos (Figura 2).

B aseados nesse conceito, os pesquisadores começaram a considerar a possibilidadedo seu transplantepara recompor tecidos destruídos por doenças, por traumas ou por terapias agressivas. De fato, o transplante de células de medula óssea tem sido feito há mais de 40 anos para recompor medulas destruídas por quimioterapia ou radiação e, dessa forma, repor as células sangüíneas, por exemplo, nas leucemias e linfomas.

\section{Histórico}

0 primeiro transplante de CTA em humanos foi feito por Thomas et al., em 1957, em gêmeos univitelinos, para tratamento de leucemia2.

$\mathrm{N}$ a década de 1960 , pesquisadores descobriram quea medula óssea contém, pelo menos, doistipos de células-tronco: as hematopoiéticas, que formam todos os tipos de células sangüíneas endoteliais e as células do estroma, uma população mista que pode gerar osso, cartilagem, gordura e tecido fibroso e conjuntivo (Figura 3).

\section{O nde as CTA são encontradas e qual seu papel fisiológico?}

As CTA são encontradas no fígado ${ }^{3}$, cérebro 4 , tecido gorduroso ${ }^{5}$ emedula óssea ${ }^{6-8}$. Estaúltimaéaque apresenta quantidade maior de células. N os outros tecidos, as células existem em pequena quantidade. Trabal ha-se, por isso, no desenvolvimento de técnicas deculturaquepropiciem o número decélulasadequado para terapia. Esse número, em geral, chega à casa dos bilhões ${ }^{9,10}$.

Supõe-se que as CTA permaneçam quiescentes (sem se dividirem) nos tecidos que constituem seu habitat, até que são ativadas por doenças, inclusive tumores ou trauma, e também para fazer a reposição de células "gastas" no organismo ao longo da vida, através da liberação, no sangue circulante, de células progeni- 


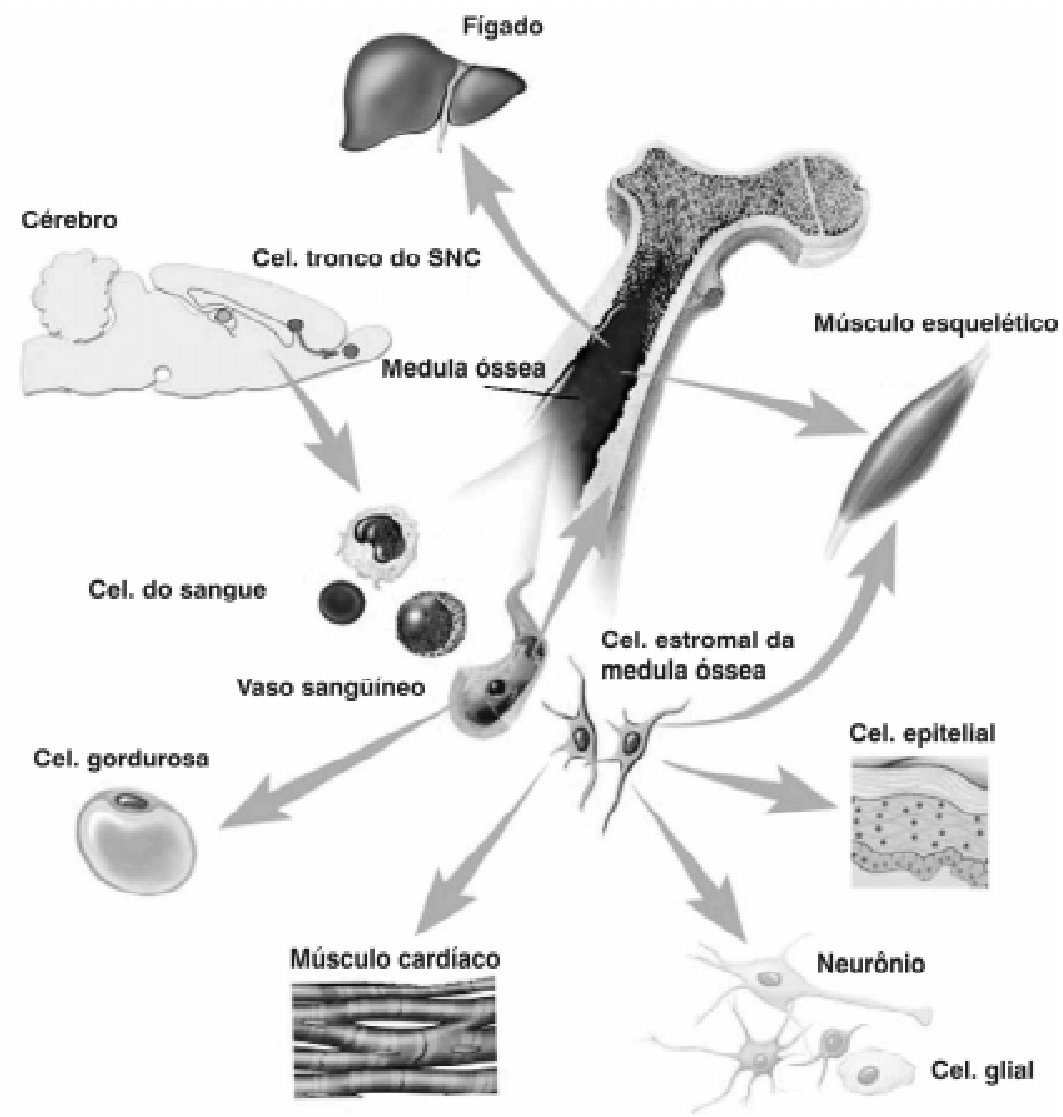

Figura 2 - D iferenciação e transdiferenciação das CT A da medula óssea e do cérebro

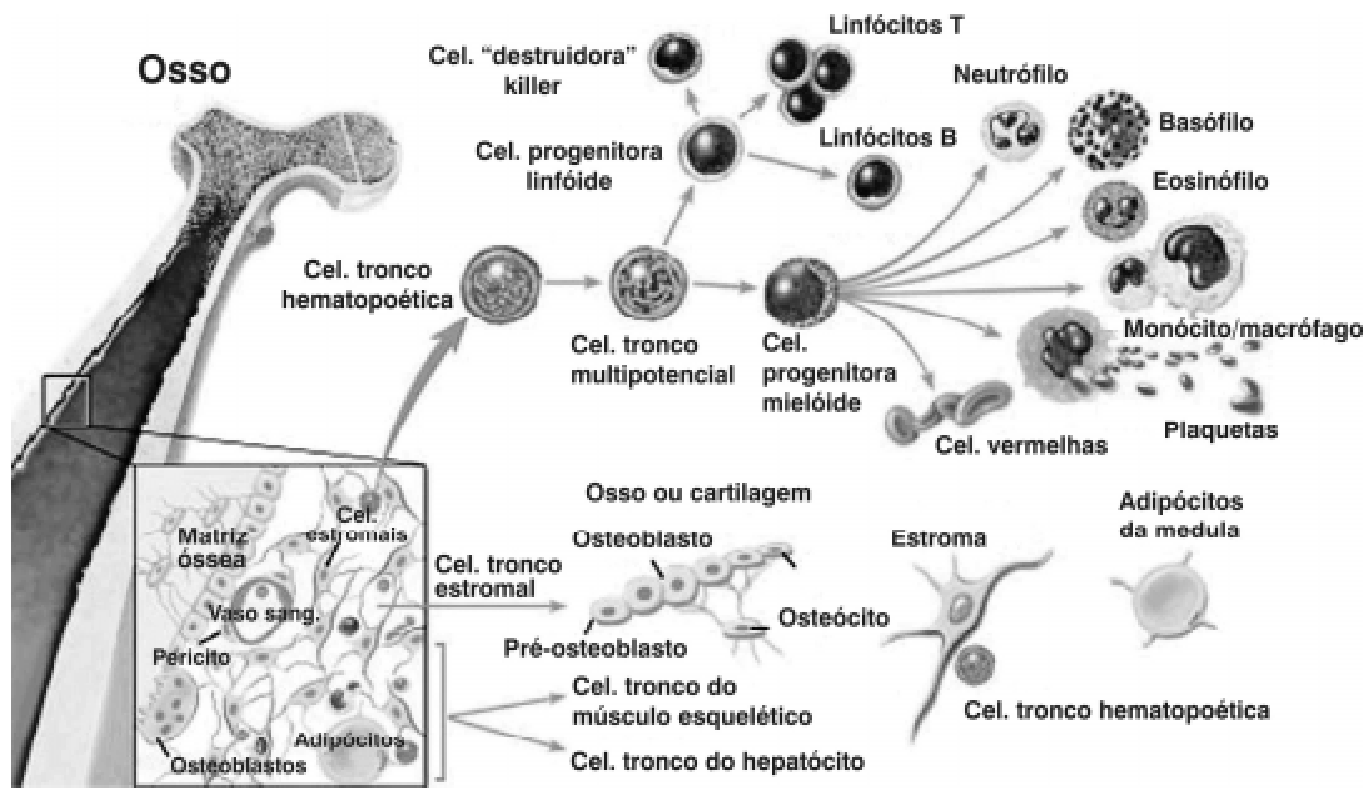

Figura 3 - CTA da medula óssea: do estroma e hematopoéticas 
toras (CP), que seriam mobilizadas para os locais onde se fizessem necessárias. Essa mobilização seria feita por substâncias liberadas no local da lesão ${ }^{11}$. Seriam, assim, uma espécie de "departamento de manutenção" que, com a idade, vai diminuindo sua intensidade de atuação. D e fato, há trabal hos mostrando que as C P circulantes diminuem com a idade $\mathrm{e}^{12-14}$.

As C $P$ agem na reparação de traumas do en dotélio, promovendo sua remodelação de forma a evitar a hiperplasia fibromuscular ${ }^{15-17}$, embora alguns trabaIhos sugiram que elas tenham participação na sua formação quando não há uma modulação adequada de sua ação ${ }^{18}$. Foi relatada a ação benéfica das $C P$ no equilíbrio do metabolismo lipídico ${ }^{19}$, e observou-se 0 aumento do seu número com a atividadefísica ${ }^{20}$ eo uso de estatinas ${ }^{21,22}$. Por outro lado, o número de $C P$ diminui com 0 aumento dos fatores de risco ${ }^{23}$, principalmente com o diabetes ${ }^{24}$ e com a doença isquêmica crônica instalada25.

Com relação aos tumores, a necessidade de proliferação vascular para irrigar os tecidos tumorais que crescem em excesso faz com que sejam liberados fatores que mobilizam as CTA da medula óssea. Tais fatores são o VEGF-R-1, VEGFR-2 (V ascular Endothelial G rowth Factor Receptor 1 e 2) e PIGF (Placenta Induced Growth Factor) ${ }^{26}$.

M ecanismos antiangiogênese dificultariam o crescimento dos tumores 27 .

Q uando a CT A não diferenciada se transforma na célula do tecido ondeela "reside", diz-sequehouveuma diferenciação. Q uando a CT A setransforma em tecido de outro órgão que não o seu, diz-se que houve uma transdiferenciação.

Com respeito ao desenvolvimento das células sangüíneas e endoteliais, parece que ambas têm o mesmo precursor: o hemangioblasto, que apareceprecocemente no embrião e desaparece rapidamente ${ }^{28}$. 0 ntogenicamente, o hemangioblasto estáligado no VEG FR-2 ${ }^{29}$. Ratos que não têm o VEG FR -2 apresentam um desvio patológico tanto nascélulas hematopoiéticas quanto na vasculatura 30,31 .

Por outro lado, célulasVEG FR-2 positivas isoladas de embriões geraram colônias mistas hematopoiéticoendoteliais quando em cultura unicelular ${ }^{32}$. Estudos adicionais mostraram que, após o nascimento, células que têm os marcadores de superfície CD 133, CD 34 e V G FR-2 formam um subconjunto de células na medula óssea, sangueperiférico esangue do cordão umbilical, que possuem atividade funcional de hemangioblastos, pois são capazes de se diferenciar tanto em células endoteliais quanto hematopoiéticas ${ }^{33}$.

\section{Células endoteliais progenitoras}

Assahara et al ${ }^{34}$ foram os primeiros a descrever a existência das células endoteliais progenitoras (CEP), sua origem na medula óssea e sua participação na formação de novos vasos em adultos. Já na década de 1960, células endoteliais circulantes (CE), derivadas das CEP, foram demonstradas em tubos de $D$ acron implantados em aortas de porcos, coelho e cão ${ }^{35}$. D a mesma forma, as CE foram demonstradas em dispositivos de assistência ventricular (coração artificial) ${ }^{36}$.

As CEP podem formar novos vasos por três mecanismos; a) angiogênese - capilares que resultariam de brotos originados de vasos já existentes 37 ; b) arteriogênese - aparecimento de vasos que estariam "adormecidos", embora alguns acreditem na possibilidade de neoformação ${ }^{38}$; c) vasculogênese - formação de novos vasos ou remodelação dos já existentes ${ }^{11}$.

Parece que a arteriogênese é o mecanismo mais eficiente para aumento da circulação (20 a 30 vezes), enquanto a angiogênese aumenta duas a três vezes e a vasculogênese ainda não foi adequadamente dimensionada 39 .

Estímulos especiais mobilizariam as CEP que poderiam produzir simultaneamente a angiogênese e a vasculogênese, imitando o processo embrionário. A arteriogênese (circulação colateral) seria produzida pelas variações no shear stress (trauma de atrito), que liberariam substâncias mobilizadoras do endotélio e ativariam CEP circulantes ${ }^{38}$.

O s estímulos para a mobilização das CTA são gerados por substâncias liberadas na zona isquêmica (milieu dependent), como o fator de crescimento endotelial VEG F, fator decrescimento dosfibroblastos FGF (Fibroblast $\mathrm{G}$ rowth Factor), citocinas, angiopoietinas e outros 39 .

O utra possibilidade é a de que as próprias CTA produziriam esses fatores de estímulo, que concorreriam para a formação de novos vasos, inclusive estimulando CP "residentes" na região isquêmica (atividade paracrina) ${ }^{40-42}$, e ainda concorreriam para a melhora do funcionamento do endotélio dos vasos remanescentes, além de promover a sua vasodilação 43 . É provável que haja uma associação desses vários mecanismos para que haja vasculogênese. 
0 que, porém, parece bem definido équeosfatores decrescimento, ascitocinas, angiopoietinaseoutrossão imprescindíveis em todo o processo e estariam todos englobados no sistema H IF (H ypoxia I nducible Factor), tendo, cada um deles, diferentes variantes tanto na sua parte ativa quanto nos seus receptores ${ }^{39}$.

Aliás, énesseconceito quesebaseiaaterapiagênica, que consiste na administração desses fatores por meio de vetores virais ou, então, plasmídeos ${ }^{44,45}$. É de se esperar, para maior eficiência, a associação das terapias gênica ecelular. N a verdade, já há trabal hos reportando essa associação 46,47 . Alguns deles sugerem, inclusive, a associação de doisfatores de crescimento, por exemplo: VEGF, que formaria tubos endoteliais muito permeáveis e FGF, que promoveria a formação das partes fibrosa e muscular ${ }^{48,49}$.

0 problema de a terapia gênica ser mais complexa e laboriosa, envolvendo riscos potenciais quando os vetoressão virais, bem como reaçõesadversasa substâncias químicas usadas no seu preparo e, ainda, de os fatores de crescimento terem vida média muito curta, será, certamente, resolvido. É esperado também que as próprias células-tronco recebam marcações genéticas novas, as quais ajudarão a tratar as doenças, inclusive transportando fatores de crescimento específicos para órgãos determinados ${ }^{50-53}$.

\section{M arcadores das células endoteliais progenitoras}

As CEP são identificadas, basicamente, de duas maneiras: pela determinação, através de anticorpos monoclonais específicos, de marcadores de superfície, como o CD $34^{+}$(Cell Diferentiation), CD $133^{+}$VEGF e outros ${ }^{51}$, que dão as características fenotípicas das células; técnicas que utilizam as reações em cadeia de polimerase (PCR) eprincipalmentea RT -PCR (Reverse T ransduction - PCR), através da qual se identificam as células pelo seu DN A 52 .

I mportante, também, élembrar que as CEP podem ter mais do que uma expressão genética de superfície: FVW (Fator de von W ilebrand), CD 45, CD 14, Eselectine, $C D 133$ eoutros ${ }^{53}$. Além disso, al gunsmarcadores de superfície, como o CD $133^{+}$, deixam de se expressar após a transformação em células endoteliais, transformando-se em CD 133- (CD 133 negativo) $)^{52}$.

A importância dos marcadores éque eles permitem separar as células e acompanhá-las, observando sua localização nos tecidos (homing) e, eventualmente, os diferentes tempos até sua diferenciação.

\section{Experimentação animal com células-tronco na isque- mia periférica}

O s resultados das experiências com células-tronco em patologias do miocárdio, doenças imunológicas, doenças e traumas neurológicos, diabetes e outras são freqüentemente entusiasmantes em animais, mas nem sempre se confirmam em humanos, nos quais as informações de sucesso variam de nulas a excelentes 39 .

N esteartigo, noslimitaremosa rever as publicações sobre isquemia periférica.

I ba et al. ${ }^{41}$ ek haldi et al. ${ }^{54}$ mostraram, em animais, que a injeção de células mononucleares circulantes ou da medula óssea melhoravam a densidade capilar em model os de membros isquêmicos.

I ba et al. ${ }^{41}$ demonstraram, em ratos, que a injeção de célulasmononucleares de medula óssea humana em membros isquêmicos provocava a formação de circulação colateral através de fatores angiogênicos, principalmente o VEG F ecitocinas, equeanticorpos anti-VEG F inibiam a formação de novos vasos.

Li Sheng et al. ${ }^{55}$ injetaram células de medula óssea préestimuladas por hipoxia ex vivo e notaram que a expressão deVEGF e de diferenciação endotelial eram maiores do que as células processadas em normoxia.

Baseadosno conhecimento dequeascélulasmesenquinais da medula podem secretar citocinas e outros fatores decrescimento, Shintani et al. ${ }^{56}$ mostraram, em animais, que a implantação de células mononucleares de medula óssea em membros isquêmicos também promovem formação de novos vasos, com incorporação deCEP em capilares, equea concentração deFG F , VEG $F$ e citocinas aumentava nos tecidos do membro implantado.

I waguro et al. ${ }^{50}$ mostraram, em ratos atímicos, que a injeção de CEP heterólogas marcadas com VEGF aumentava a circulação mais do queem animaiscontrole (injeção de CEP sem VEGF). Seria um caso de associação de terapia gênica e celular.

Silvestre et al. ${ }^{57}$ demonstraram, em ratos, a importância da interleucina-10, um agente antiinflamatório, na neovasculogênese. A presença de inflamação (ratos interleucina negativos) favorecia a angiogênese, enquanto que a diminuição da inflamação (ratos interleucina positivos) diminuía a angiogênese pela regulação, para baixo, do VEG F. A presença de inflamação, portanto, seria um fator positivo para a neovasculogênese. 


\section{Experiências clínicas com células-tronco adultas}

Como seqüência do trabalho de Shintani ${ }^{55}$, Yuyama et al. publicaram, em $2002^{58}$, sua experiência clínica com 47 pacientes, nos quais fizeram randomização (não duplo-cego). 0 s pacientes eram divididos em dois grupos: 25 apresentavam isquemia crítica unilateral (grupo A) e 22 bilateral (grupo B). N o grupo A, foram injetadas células mononucleares da medula óssea na perna com isquemia crítica e soro fisiológico na perna contralateral. No grupo B, foram injetadas células mononucleares da medula óssea em uma das pernas e células mononucleares do sangue periférico na outra.

Foi observada a diminuição da dor na maioria dos pacientes de ambos os grupos injetados com células mononucleares da medula óssea. Esses pacientes também mostraram melhora significativa do índice tornozelo/braço, da pressão transcutânea de oxigênio, e, aos 6 meses, a angiografia mostrou melhora notável na circulação colateral em 27 dos 47 pacientes (15 no grupo $A$ e 12 no grupo $B$ ). Em um pacientequemorreu de infarto do miocárdio 3 meses após o implante, o estudo histológico de fragmentos do gastrocnêmico revelou aumento grande da vascularização (relação músculo/capilares), quando comparado com o membro em que se injetou salina. A dor desapareceu em 22 pacientes (12 no grupo A e 10 no grupo B) e houve melhora da dor em repouso em 15 pacientes (nove no grupo $A$ e seis no grupo B). A amputação de dedos foi evitadaem 15 de 20 pacientes (oito no grupo A eseteno grupo $B$ ). H ouvemelhora deúlcerasisquêmicas em seis de 10 pacientes (três em cada grupo).

0 grupo de pernas injetado com células mononucleares do sangue periférico mostrou resultados menos significativos.

Os autores sugerem que as células implantadas liberam fatores angiogênicos e citocinas. Entretanto, como o nível desses fatoresno sanguenão aumenta após a injeção das células, reforçam a sugestão deadministração simultânea de uma combinação de fatores: VEG F para estimular a formação de tubos endoteliais e FGF para produzir mioblastos para a "maturação" dos vasos neoformados.

Yamamoto et al. ${ }^{25}$ demonstraram que as CEP circulantes estão diminuídas em pacientes com isquemia de membros e podem aumentar muito pelo implante de células mononucleares de medula óssea e de sangue periférico autógenas, produzindo efeito angiogênico.
Kawamura et al. ${ }^{59}$ informaram a prevenção de amputação em pacientes com úlceras isquêmicas pelo implante de células mononucleares autógenas do sangue circulante.

$\mathrm{H}$ uang et al. ${ }^{60}$ indicaram as células-tronco do sangue periférico autógeno como tratamento para isquemias graves de membros inferiores de origem aterosclerótica.

$H$ igashi et al. ${ }^{43}$ demonstraram que o implante de células mononucleares de medula óssea melhorava a vasodilatação dependente do endotélio em pacientes com isquemia demembros inferiores, isto é, mel horava o desempenho do endotélio dos vasos remanescentes.

Yang et al. ${ }^{61}$ reportaram o uso, com bons resultados, de células-tronco no tratamento de isquemia dos membros inferiores em 62 pacientes.

Ramirez et al. ${ }^{62}$ apresentaram um caso de transplante de células-tronco em paciente com isquemia crítica demembro inferior elesão trófica, com excelente resultado após 24 semanas.

Como se trata de uma técnica nova, há algumas perguntas importantes, cujas respostas vão depender de pesquisa e experiência:

- Q ual o exato mecanismo pelo qual ascélulas-tronco se diferenciam ou transdiferenciam para formar novos tecidos? A leitura de trabalhos de pesquisa básica, de experiência em animais e de pesquisa clínica ainda não responde a essa pergunta. 0 desenvolvimento de técnicas adequadas de marcação celular e de genes, assim como a identificação passo a passo de fatores de crescimento, citocinas e outras substâncias envolvidas, poderá ajudar.

- Quais os riscos envolvidos no uso de célulastronco? Q uando se usam células embrionárias, 0 risco de desenvolvimento de tumores, bem como de malformações genéticas, é considerado importante. $\mathrm{H}$ averia necessi dade de mecanismos de modulação da proliferação e diferenciação das células. As CTA, como já foi dito, já cumpriram as fases evolutivas mais precoces e, portanto, ofereceriam menos riscos.

- Q ual o número ideal de CTA para se obter efeito terapêutico? C linicamente, há sugestões para quese useum mínimo de $2 \times 10^{9} 57$. Parecequea resposta terapêutica é número dependente.

- É previsto o implante de células-tronco mais de uma vez no mesmo paciente? Embora não haja experiência, essa possibilidade poderá ser consi- 
derada, dependendo da resposta ao primeiro implante.

- 0 resultado esperado do implante de CTA é o mesmo para os diferentes tipos de doenças vasculares(inflamatórias, degenerativas)? Só a experiência clínica responderá. Se a isquemia for o único fator desencadeante, épossível quesim. Entretanto, seos fatores etiopatogênicos, que são diferentes, influírem no processo, épossível quenão. A té o momento, as evidências são de que só a hipóxia éresponsável pela regulação para cima da sensibilidade dos receptores de VEGF em FGF e outros fatores angiogênicos, portanto a etiologia da doença não seria importante.

- Q ual o tipo preferencial deCTA a ser implantado? M esenquimal? Células mononucleares? São ainda escassos os trabalhos de pesquisa com células mesenquimais. Sabe-se que são pouco numerosas e necessitam ser cultivadas para aumentar seu número. Teriam, por outro lado, maior capacidade de transdiferenciação. As células mononucleares são mais numerosas, mas mais limitadas em sua capacidade de gerar novos tecidos. São mais práticas para tratamento de isquemia crítica.

- Devem-se usar os fatores de crescimento como estimuladores da mobilização ou mesmo associadosàs CTA? Conforme já dito, éum objetivo a ser perseguido.

- Q uaisaslimitações do uso deCTA? N ão há, ainda, evidências de que as CT A possam se diferenciar em todos os tipos de tecidos. Poderá haver necessidade de culturas para aumentar o número e atingir o nível terapêutico. Finalmente, embora sejam ontogenicamente mais desenvolvidas que as células embrionárias, podem, por outro lado, conter mais anormalidades do D N A causadas pelas exposições a toxinas, luz solar e erros ontogênicos ocorridos durante a vida. Repetimos, porém, que esses riscos são menores do que os que existem com as células embrionárias.

- Há possibilidade de se construírem enxertos vasculares com células-tronco?T eoricamentesim, mediante técnicas de implante das células no peritôneo do próprio pacientesobremoldes e estímulos especiaise, ainda, mediante cultura de células e tecidos.

Para encerrar este artigo, devemos dizer que o uso de CT A é uma grande promessa terapêutica, mas, por enquanto, éapenasuma promessa. $\mathrm{N}$ o momento, o que temos é um conjunto relativamente discordante de teorias que, espera-se, chegará a um consenso.

T rabalhos intensos e profundos de pesquisa básica e animal devem continuar, e os resultados de pesquisas clínicas só poderão ser considerados como eficientes após estudos randomizados, duplo-cego, com número estatisticamente adequado e, principalmente, após otimização do tratamento clínico/cirúrgico com os métodos de tratamento já consagrados.

O futuro exigirá muito trabalho e investimento.

\section{R eferências}

1. Thomson JA, Kovitz-Eldor J, Shapiro SS, et al. Embryonic stem cell lines derived from human blastocysts. Science. 1998;282:114-17.

2. Thomas ED, Lochte Jr H , Cannon JH, et al. Supralethal whole body irradiation and isologous marrow transplantation in man. J Clin Invest. 1959;38(10 pt 1-2):1709-16.

3. Alison M , Sarraf C. H epatic stem cells. J H epatol. 1998;29: 676-82.

4. Gage FH. Mammalian neural stem cells. Science. 2000;287:1433-8.

5. Planat-Benard V, Silvestre JS, Cousin B, et al. Plasticity of human adipose Lineage Cells toward endothelial cells: Physiological and therapeutic perspectives. Circulation. 2004;109:656-63.

6. Pittenger M F, M ackay AM, Beck SC, et al. M ultilineage potential of adult human mesenchymal stem cells. Science. 1999;284:143-7.

7. O lic D, Kajstura J, Chimenti $S$, et al. Bone marrow cells regenerate infracted myocardium. $N$ ature. 2001;410:701-5.

8. Shi $B Q$, Raffi $S, W$ u M H , et al. Evidencefor circulating bone marrow-derived endothelial cells. Blood. 1998;92:362-7.

9. Reys $M$, Lund $T$, Lenvik $T$, et al. Purification and ex vivo expansion of postnatal human marrow mesodermal progenitor cells. Blood. 2001;98:2615-25.

10. Yoon YS, W ecker $A, H$ eyd $L$, et al. Clonally expanded novel multipotent stem cells from human bone marrow regenerate myocardium after myocardial infarction. J Clin Invest. 2005;115:326-38.

11. Asahara T, M asudaH,$T$ akahashi $\mathrm{T}$, et al. Bonemarrow origin of endothelial progenitor cells responsible for postnatal vasculogenesis in physiological and pathological neovascularization. Circ Res. 1999;85:221-8.

12. M inamino $T$, M iyauchi $H$, Yoshida T, et al. Endothelial cell senescence in human atherosclerosis role of telomere in endothelial dysfunction. Circulation. 2002;105:1541-4.

13. Rauscher FM, Goldschmidt-Clermont PJ, D avis BH, et al. Aging progenitor cell exhaustion, and atherosclerosis. Circulation. 2003;108:457-63.

14. Shimada T, T akeshita Y, M uroharaT, et al. Angiogenesisand vasculogenesis are impaired in the precocious-aging klotho mouse. Circulation. 2004;110:1148-55. 
15. Sata M. Circulating vascular progenitor cells contribute to vascular repair, remodeling, and lesion formation. Trends Cardiovasc M ed. 2003;13:249-53.

16. Gulati R, Jevremovic D, Peterson TE, et al. Autologous culture-modified mononuclear cellsconfer vascular protection after arterial injury. Circulation. 2003;108:1520-6.

17. FujiyamaS, Amano K, U ehiraK, et al. Bonemarrow monocyte lineage cells adhere on injure endothelium in a monocyte chemoattractant protein-1-dependent manner and accelerate reendothelialization as endothelial progenitor cells. Cir Res. 2003;93:980-9.

18. Sata M , Sai ura A, Kunisato A, et al. H ematopoietic stem cells differentiate into vascular cells that participate in the pathogenesis of atherosclerosis. $\mathrm{N}$ at M ed. 2002;8:403-9.

19. Boisvert W A, Spangenberg J, C urtiss LK, et al. T reatment of severe hypercholesterolemia in apolipoprotein E-deficient mice by bone marrow transplantation. J Clin Invest. 1995;96:1118-24.

20. Rehman J, Li Jingling, Parvathaneni $L$, et al. Exercise acutely increasescirculating endothelial progenitor cellsand monocyte/ macrophage-derived angiogenic cells. J Am Coll Cardiol. 2004;43:2314-8.

21. D immeler $\mathrm{S}, \mathrm{Aicher} A, \mathrm{~V}$ asa $\mathrm{M}$, et al. H M G-CoA reductase inhibitors(statins) increaseendothelial progenitor cellsvia the PI 3-Kinase/Akt pathway. J Clin Invest. 2001;108:391-7.

22. V asa M, Fichtlscherer $S$, Adler $K$, et al. Increase in circulating endothelial progenitor cells by statin therapy in patients with stablecoronary artery disease. Circulation. 2001;103:2885-90.

23. H ill JM, Zalos G, H alcox JP, et al. Circulating endothelial progenitor cells, vascular function, and cardiovascular risk. N Engl J M ed. 2003;348:593-600.

24. W altenberger J, Lange J, Kranz A, et al. Vascular endothelial growth factor-A-induced chemotaxis of monocytes is attenuated in patients with diabetes mellitus. A potential predictor for the individual capacity to develop collaterals. Circulation. 2000;102:185-90.

25. Yamamoto $K$, Kondo $T$, Suzuti S, et al. M olecular evaluation of endothelial progenitor cellsin patientswith ischemic limbs. Arterioscler Thromb V asc Biol. 2004;24:e192-6.

26. M ancuso $P$, Burlini $A$, Pruneri $G$, et al. Resting and activated endothelial cells are increased in the peripheral blood of cancer patient. Blood. 2001:97:3658-61.

27. D avidoff AM, N g CY, Brown P, et al. Bonemarrow-derived cells contribute to tumor neovasculature and, when modified to express an angiogenesisinhibitor, can restrict tumor growth in mice. Clin Cancer Res. 2001;7:2870-9.

28. Ribatti $D, V$ acca A, Roncali $L$, et al. Hematopoiesis and angiogenesis: a link between two apparently independent processes. J H aemother Stem Cell Res. 2000;9:13-9.

29. Eichmann A, Corbel $C, N$ ataf $V$, et al. Ligand-dependent development of the endothelial and hemopoietic lineages from embryonic mesodermal cells expressing vascular endothelial growth factor receptor-2. Proc $\mathrm{N}$ atl.Acad Sci USA. 1997;94:5141-6.

30. Shalaby F, Rossant J, Yamaguchi TP, et al. Failure of bloodisland formation and vasculogenesis in FLK-1 deficient nice. N ature. 1995;376:62-6.

31. Shalaby $F, H$ o J, Stranford $W L$, et al. A requirement for flk1 in primitiveand definitivehematopoiesisand vasculogenesis. Cell. 1990;89:981-90.
32. N ishikawa SI, N ishikawa S, H irashima M, et al. Progressive lineage analysis by cell sorting and culture identifies FLK +VE cadherin+cells at a diverging point of endothelial and hematopoietic lineages. D evelopment. 1998;125:47-1757.

33. Ribatti D, V accaA, N ico B. C ross-talk between hematopoiesis and angiogenesis signaling pathways. Curr $\mathrm{Mol} \mathrm{Med}$. 2002;2:537-47.

34. Asahara T, M uroharaT, Sullivan A, et al. I solation of putative progenitor endothelial cells for angiogenesis. Science. 1997;275:964-7.

35. Stump M M , Jordan G L J r, D eBakey M E, et al. Endothelium grown from circulating blood on isolated intravascular $D$ acron hub. Am J Pathol. 1993;43:361.

36. Frazier $\mathrm{OH}$, Baldwin RT, Eskin SG, et al. I mmunochemical identification of human endothelial cells on the lining of a ventricular assist device. T exas H eart Inst J. 1993;2:78.

37. Carmeliet $P$. M echanisms of angiogenesis and arteriogenesis. $\mathrm{N}$ at $\mathrm{M}$ ed. 2000;6:389-95.

38. Schaper W, Secholz D. Factors regulating arteriogenesis. Thromb Vasc Biol. 2003;23:1143-51.

39. SimonsM . Angiogenesis. W heredo westand now? Circulation. 2005;111:1556-66.

40. W ang JS, Shum Tim D, Galipeau J, et al. M arrow stromal cells for cellular cardiomyoplasty feasibility and potential clinical advantages. J T horac C ardiovasc Surg. 2000;120:9991005.

41. I ba $O, M$ atsubara $H, N$ ozawa $Y$, et al. Angiogenesis by implantation of peripheral blood mononuclear cells and plateletsinto ischemic limbs. Circulation. 2002;106:2019-25.

42. Rehman J, Li J, O rschell CM, M arch KL. Peripheral blood "endothelial progenitor cells" are derived from monocyte/ macrophages and secrete angiogenic growth factors. Circulation. 2003;107:1164-9.

43. H igashi $Y, K$ imura $M, H$ ara $K$, et al. Autologous bonemarrow mononuclear cell implantation improvesendotheliumdependent vasodilation in patients with limb ischemia. Circulation. 2004;109:1215-8.

44. Herttuala SY, Alitalo K. G ene transfer as a tool to induce therapeutic vascular growth. $N$ at M ed. 2003;9:694-701.

45. Comerota AJ, Throm RC, M iller KA, et al. $\mathrm{N}$ aked plasmid D N A encoding fibroblast growth factor typel for thetreatment of end-stage unreconstructible lower extremity ischemia: preliminary results of a phase I trial. J V asc Surg. 2002;35: 930-6.

46. Raffi $\mathrm{S}, \mathrm{H}$ eissig $\mathrm{B}, \mathrm{H}$ attori $\mathrm{K}$. Efficient mobilization and recruitment of marrow-derived endothelial and hematopoietic stem cells by aden oviral vectors expressing angiogenic factors. Gene Ther. 2002;9:631-41.

47. T akahashi $\mathrm{T}, \mathrm{KalkaC}, \mathrm{M}$ asudaH , et al. I schemiaand cytokineinduced mobilization of bone marrow-derived endothelial progenitor cells for neovascularization. $N$ at $M$ ed. 1999;5: 434-8.

48. Asahara T, Bauters C, Zheng LP, et al. Synergistic effect of vascular endothelial growth factor and basic fibroblast growth factor on angiogenesis in vivo. Circulation. 1995;92(9 Suppl):II365-71.

49. H attori K, Dias S, H eissig B, et al. Vascular endothelial growth factor and angiopoietin-1 stimulate postnatal hematopoiesis by recruitment of vasculogenic and hematopoietic stem cells. J Exp M ed. 2001;193:1005-14. 
50. I waguro $\mathrm{H}, \mathrm{Yamaguchi}$ J, $\mathrm{KalkaC}$, et al. Endothelial progenitor cell vascular endothelial growth factor genetran ffer for vascular regeneration. Circulation. 2002;105:732-8.

51. Gross $P, H$ erbrig K. Role of endothelial progenitor cells in cardiovascular pathology. Annales Academiae M edicae Bialostocenis. 2004;49:174-7.

52. Rafii S. Circulating endothelial precursors: mystery, reality, and promise. J Clin Invest. 2000;105:17-19.

53. Peichev $M, N$ aiyer $A$ J, , et al. Expression of VEGFR-2 and AC 133 by circulating human CD 34 cells identifies a population of functional endothelial precursors. Blood. 2000;95:952-8.

54. K haldi AA, Sabti H, G alipeau J, et al. Therapeutic angi ogenesis using autologous bone marrow stromal cells: improved blood flow in a chronic limb ischemia model. Ann Thorac Surg. 2003;75:204-9.

55. Li Sheng T, H amano K, Suzuki K, et al. I mproved angiogenic potency by implantation of ex vivo hypoxia prestimulated bone marrow cells in rats. Am J Physiol H eart Circ Physiol. 2002;283:H 468-73.

56. Shintani S, M urohara $T$, Ikeda $H$, et al. Augmentation of postnatal neovascularization with autologous bone marrow transplantation. Circulation. 2001;103:897-903.

57. Silvestre JS, M allat Z, D uriez $M$, et al. Antiangiogenic effect of interleukin-10 in ischemia-induced angiogenesis in mice hindlimb. Cir Res. 2000;87:448-52.

58. Yuyama ET, M atsubara $\mathrm{H}, \mathrm{M}$ urohara $\mathrm{T}$, et al. Therapeutic angiogenesis for patients with limb ischaemia by autologous transplantation of bone-marrow cells: a pilot study and a randomized controlled trial. Lancet. 2002;360:427-35.
59. Kawamura A, H orie T, T suda I, et al. Prevention of limb amputation in patients with limbs ulcers by autologous peripheral blood mononuclear cell implantation. Ther Apher Dial. 2005;9:59-63.

60. H uang PP, Li SZ, H an M Z, et al. Autologoustransplantation of peripheral blood stem cells as an effective therapeutic approach for severe arteriosclerosis obliterans of lower extremities. Thromb H aesmost. 2004;91:606-9.

61. Yang XF, W u YX, W ang H M , et al. Autologous peripheral blood stem cells transplantation in treatment of 62 cases of lower extremity ischemic disorder. Zhonghnua $\mathrm{N}$ ei $\mathrm{Ke} \mathrm{Za}$ Zhi. 2005;44:95-8.

62. Ramirez PM, Balea ED, Padron $\mathrm{CH}$, et al. Trasplante de células madre autólogas en el miembro inferior isquémico de un pacientecon arteriosclerosisobliterantecrítica. Rev Cubana H ematol. Inmunol H emoter. 2005;21:33-8.

Correspondência:

José $D$ almo de Araújo

Rua C astelo D 'Água, 3030, Redentora

Cx. postal 461

CEP 15015-210 - São J osé do Rio Preto, SP

\section{Aviso aos ex-residentes}

Se você foi residente até 2004 e ainda não está inscrito em sua Regional, procure regularizar sua situação para passar a receber $0 \mathbf{J}$ Vasc $\mathbf{B r}$ imediatamente, sem qualquer ônus.

Ajude a manter o cadastro da SBACV atualizado. 